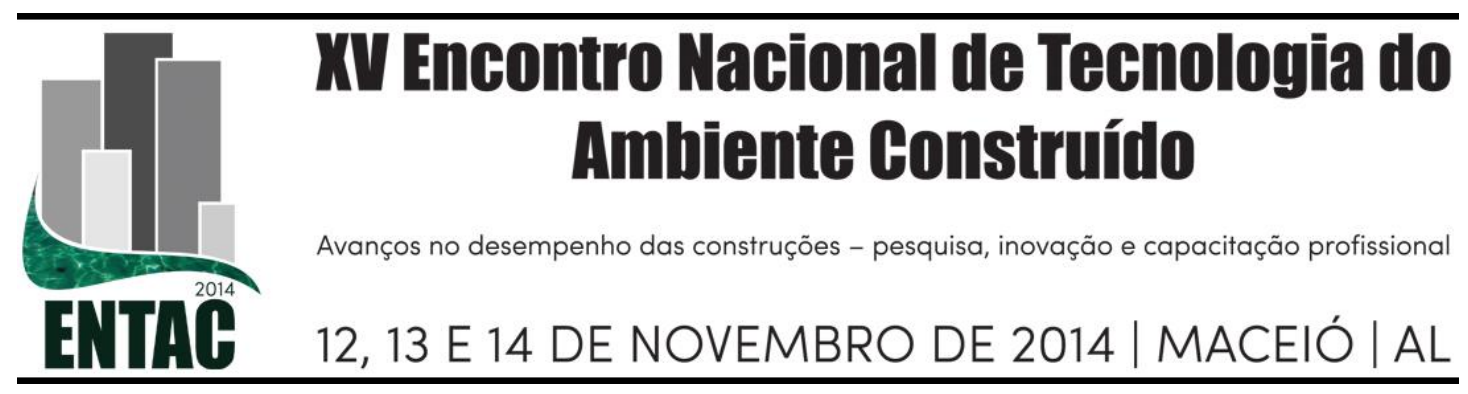

\author{
REVISÃO DE INSTRUMENTO DE AVALIAÇÃO DE \\ ACESSIBILIDADE ESPACIAL \\ SOUZA, Rodrigo Acosta de (1); BINS ELY, Vera Helena Moro (2); CAMPOS, \\ Rafael Alves de (3); DORNELES, Vanessa Goulart (4); SILVA, Lucas Luciani da \\ (5); \\ (1) UFSC, (48)96097011, rodrigoacostadesouza@gmail.com, (2) UFSC, vera.binsely@gmail.com, (3) \\ UFSC, arqrafaelcampos@gmail.com, (4) UFFS, arq.vanessagdorneles@gmail.com, (5) UFSC, \\ lucaslucianidasilva@gmail.com.
}

\begin{abstract}
RESUMO
Este artigo busca apresentar os resultados parciais de uma pesquisa ainda em andamento cujo objetivo é a revisão de um instrumento de avaliação de acessibilidade espacial já existente, buscando-se estabelecer critérios de adaptação para uma possível digitalização desta ferramenta. Utilizou-se como base para o estudo as planilhas de avaliação de acessibilidade espacial do Ministério Público de Santa Catarina. Para a revisão, buscou-se entender sua aplicação através de entrevistas e utilização em uma avaliação-piloto, que serviram de base para o processo de adaptação.
\end{abstract}

Palavras-chave: Acessibilidade Espacial, Avaliação de Acessibilidade, Edificações.

\begin{abstract}
This paper looks for presenting the partial results of a still in progress research with the purpose to review an already existing instrument for spatial accessibility evaluation, looking forward to establish adjustment criteria for a possible digitalization of the tool. There were used as a basis to this study the spreadsheets for spatial accessibility evaluation from the Public Ministry of Santa Catarina - Brazil. To review them, it was intended to understand their use through interviews and their application on a pilot-evaluation, which served as a base to the adaptation process.
\end{abstract}

Keywords: Spatial Accessibility, Accessibility Evaluation, Buildings.

\title{
1 INTRODUÇÃ̃O
}

A preocupação com políticas de acessibilidade no Brasil é um tema de discussão constante em diversas esferas governamentais. Acessibilidade está diretamente vinculada ao conceito de cidadania, pois trata do acesso à moradia, ao trabalho e a serviços essenciais como saúde, reabilitação, educação, lazer e cultura (FÁVERO, 2004). Para a garantia de tal direito, assegurado pela Constituição Federal de 1988, são necessárias mudanças culturais, atitudinais e, também, a implementação de ações políticas e legislativas que garantam a inclusão. Entre estas, destaca-se a promoção de mudanças no ambiente construído visando atingir melhores condições de acessibilidade espacial a seus usuários.

De acordo com o Decreto-lei n ${ }^{0} 5.296$ de 2004, as edificações de uso público teriam trinta meses, a partir de sua publicação, para serem adaptadas de acordo com a norma brasileira de acessibilidade. Dessa forma, buscava-se permitir o acesso a todos os indivíduos, proporcionando-lhes independência na realização das atividades. Entretanto, verifica-se 
que mesmo sete anos após findo o prazo (em 2007), diversas edificações ao longo de todo o país ainda necessitam de adequação.

Para que sejam desenvolvidas as mudanças de forma a atender ao decreto e à norma brasileira de acessibilidade, NBR9050, é necessário que se realizem previamente avaliações das condições de acessibilidade dos edifícios. Estas servem de subsídio para o desenvolvimento de projetos arquitetônicos que garantam efetiva adequação espacial e possível inclusão. As etapas deste processo estão esquematizadas na Figura 1.

\section{Figura 1 - Etapas do processo de uma adequação espacial}

Verificar condições de

acessibilidade, buscando

obter subsídios para o projeto.

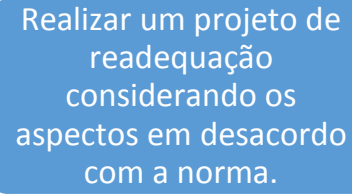

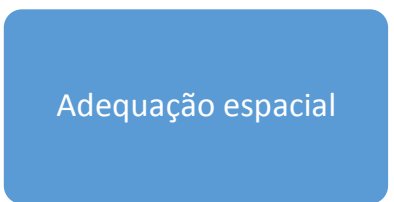

Fonte: Desenvolvido pelos autores

O presente artigo baseia-se em um projeto de pesquisa de iniciação científica ainda em andamento, o qual se propõe a revisar um instrumento de avaliação de acessibilidade espacial já existente, considerando sua possível adaptação na forma de uma ferramenta digital. Para realização do estudo, foram tomadas como base as Planilhas de Avaliação desenvolvidas no Programa de Acessibilidade às Pessoas com Deficiência ou Mobilidade Reduzida nas Edificações de Uso Público do Ministério Público de Santa Catarina. Tais planilhas foram desenvolvidas por Dischinger, Bins Ely e Piardi (2012) a partir do ano de 2002, para sistematizar o processo de avaliação. A digitalização do instrumento teria como objetivo agilizar a realização das vistorias e a geração de laudos técnicos, facilitando este processo em parques edilícios numerosos.

Este trabalho é estruturado expondo inicialmente o referencial teórico estudado acerca do tema, para melhor entendimento dos conceitos abordados. Posteriormente está descrita a metodologia utilizada, seguida dos resultados parciais obtidos até o momento e de considerações finais.

\section{REFERENCIAL TEÓRICO}

O Decreto-lei 5.296/04 define acessibilidade como "condição para utilização com segurança e autonomia, total ou assistida, dos espaços, mobiliários e equipamentos urbanos, das edificações, (...), sistemas e meios de comunicação e informação". A NBR 9050/04 cita que um espaço acessível "pode ser percebido e utilizado em sua totalidade por todas as pessoas, inclusive aquelas com mobilidade reduzida".

ELALI et al. (2010) defendem que este termo se refere a "uma gama de variáveis relacionadas às possibilidades de acesso a um local", considerando "aspectos que vão desde a identificação das trajetórias das pessoas ao se deslocarem em/para áreas específicas e as atividades que ali ocorrem".

Para este estudo, especifica-se a concepção de Dischinger, Bins Ely e Piardi (2012) de Acessibilidade Espacial. O conceito abordado pelas autoras define o direito de chegar a um local, compreender suas funções, organizações, relações espaciais e utilizá-lo com independência, segurança e conforto, participando das atividades que ali ocorrem. É importante destacar que este direito não favorece apenas pessoas com deficiência, pois 
trata de "medidas técnico-sociais destinadas a garantir o acolhimento de todos os usuários em potencial” (COHEN, DUARTE e BRASILEIRO, 2012, p40).

Para proporcionar boas condições de acesso, os ambientes devem atender requisitos básicos de naturezas diversas. Dischinger, Bins Ely e Piardi (2012) os classificam em quatro componentes: orientação espacial, deslocamento, uso e comunicação. afirmam que a garantia da acessibilidade em um ambiente depende do atendimento desses componentes em sua totalidade. Dependendo das condições dos usuários e de suas necessidades, caso apenas um deles não seja cumprido, todos os demais ficam comprometidos.

As autoras ratificam que "cada componente estabelece um conjunto de diretrizes que definem características espaciais”, as quais são aqui explicadas brevemente.

A orientação espacial se refere às características do ambiente ligadas à compreensão do espaço: reconhecimento, compreensão das atividades, definição de rotas, etc. A este componente estão relacionadas diversas características do ambiente e adicionais à ele, como a configuração espacial adotada, a legibilidade do espaço, a sinalização presente, entre outros.

A comunicação diz respeito à possibilidade de troca de informações interpessoais, ou troca de informações por meio da utilização de equipamentos de tecnologia assistiva. Atribuem-se a este componente ações como perguntar informação a outra pessoa (interpessoal) ou pedir autorização para adentrar em um ambiente através de um interfone (tecnologia assistiva).

$\mathrm{O}$ deslocamento se refere à possibilidade de movimentos em trajetos horizontais e verticais de forma segura, independente e confortável. Neste componente enquadram-se as características relativas aos trajetos percorridos pelos usuários como corredores, escadas e rampas, elevadores, etc.

Por fim, o último componente concebido pelas autoras, o uso, está relacionado com a possibilidade efetiva de participação e realização das atividades utilizando os equipamentos presentes no ambiente. A este componente referem-se aspectos relativos, por exemplo, ao mobiliário adotado em um determinado local, se permite a utilização por diversos usuários, se é seguro, entre outros aspectos.

Após a aproximação com o conceito de Acessibilidade Espacial e descrição de seus componentes - necessárias para a compreensão do instrumento de avaliação estudado - a seguir serão explicadas as etapas referentes ao processo de sua revisão e adaptação.

\section{METODOLOGIA}

Esta é uma pesquisa descritiva, de abordagem qualitativa, na qual se aplicaram procedimentos técnicos de caráter experimental com objetivo principal de revisar o instrumento de avaliação de acessibilidade espacial, já existente.

Com o intuito de entender sua utilização, optou-se por um método de inquirição, realizando uma entrevista não estruturada (MARCONI e LAKATOS, 2010) com os arquitetos responsáveis pelas avaliações do MP-SC (Ministério Público de Santa Catarina). A partir dessa abordagem, buscou-se verificar alguns pontos-chave a respeito da ferramenta, como: descobrir se ainda era utilizada, como é aplicada, que tipo de documento é capaz de gerar, suas potencialidades e deficiências, entre outros. Também buscou-se compreender o processo de avaliação de diversas edificações públicas, realizado em 2005, com esse instrumento. 
A seguir aplicou-se o método de observação sistemática do ambiente, utilizando as planilhas originais como técnica de checklist, em uma avaliação-piloto de edifício educacional em Instituição Superior de Ensino. O objetivo da aplicação deste método foi compreender a utilização do instrumento, analisá-lo criticamente em relação a sua usabilidade e gerar um laudo técnico do edifício.

O próximo passo foi a revisão da ferramenta, onde foram verificadas as perguntas nas quais se baseia a vistoria. Estas foram avaliadas de acordo com sua continuidade, redação e normas técnicas nas quais se apoiam. Durante esta revisão também foram pensados aspectos referentes à adaptação do instrumento, visando sua possível digitalização.

Como essa pesquisa encontra-se em desenvolvimento, cabe ressaltar que o experimento aqui demonstrado apoiou-se apenas na revisão e adaptação da primeira planilha (referente às áreas de acesso ao edifício). Optou-se por esta escolha por se tratar da mais extensa dentre as seis existentes, além de possuir diversas perguntas que se repetem nas demais planilhas.

\section{RESULTADOS}

\subsection{Entrevista com o Ministério Público de Santa Catarina}

A entrevista realizada com os atuais responsáveis pela avaliação no MP-SC. tinha como objetivo entender como são realizadas atualmente as vistorias, os laudos-técnicos e os termos de ajustes de conduta. Além disso, verificar se o instrumento estudado, idealizado há 10 anos com a presença do Ministério, ainda é utilizado. O encontro aconteceu com a presença dos pesquisadores e de dois funcionários do órgão: uma arquiteta e um servidor administrativo que acompanhou o processo de utilização das planilhas em 2005.

Através da entrevista pode-se descobrir que atualmente as avaliações ocorrem após solicitação da Promotoria Pública, geradas a partir de denúncias, por parte de seus usuários, quanto a irregularidades presentes nas edificações. Após a vistoria é realizado um laudo-técnico sobre a avaliação, o qual é encaminhado a um promotor de justiça, que fica encarregado de realizar o termo de ajuste de conduta. Neste documento existem recomendações de adequações espaciais que precisam ser realizadas.

Sobre o programa de avaliação no qual o instrumento estudado foi criado, em 2005, descobriu-se que o MP-SC desenvolveu um software específico para a geração de laudostécnicos. Este se baseia na estrutura de disposição de informações das planilhas, para sintetizar as informações obtidas nas vistorias. Para isso, todas as respostas e observações devem ser inseridas no computador, após preenchimento manual das planilhas durante as vistorias. O resultado final é um documento como no modelo exposto na Figura 1.

Figura 1 - Modelo de um trecho do laudo automático gerado pelo software do

Ministério Público - SC

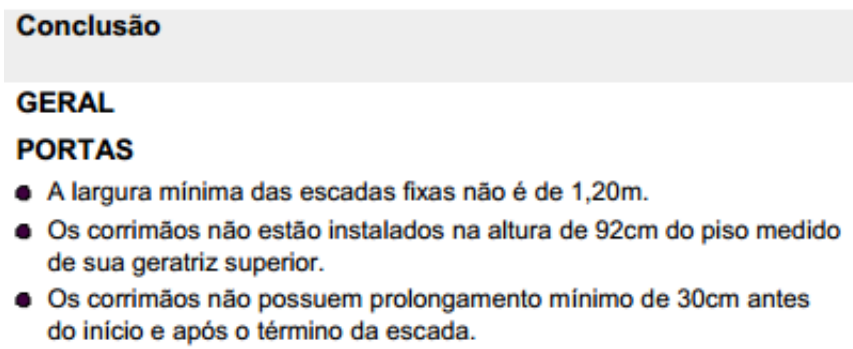

- A largura mínima das escadas fixas não é de $1,20 \mathrm{~m}$.

- Os corrimãos não estão instalados na altura de $92 \mathrm{~cm}$ do piso medido de sua geratriz superior.

- Os corrimăos não possuem prolongamento mínimo de $30 \mathrm{~cm}$ antes do início e após o término da escada.

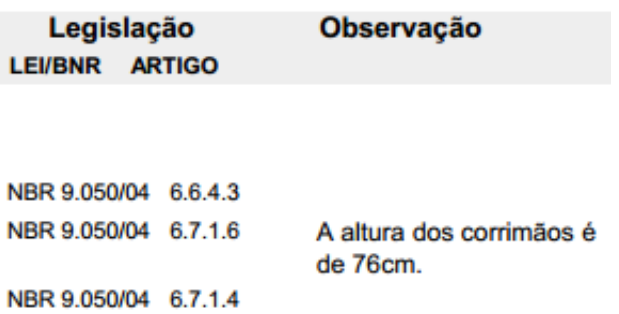

NBR 9.050/04 6.7.1.4 
Quanto à utilização das planilhas, a arquiteta respondeu que não as utiliza simultaneamente à avaliação, relatando que após diversas vistorias já decorou o instrumento e se familiarizou com a ordem das informações a serem preenchidas. Prefere realizar uma primeira análise geral do ambiente com a ferramenta em mãos, porém sem utilizá-la como roteiro. Após esta verificação, responde às perguntas no próprio local, voltando ao ambiente desejado para uma vistoria mais específica, caso sinta necessidade. Disse ainda que costuma realizá-las sozinha pela falta de contingente e que não utiliza o software para a realização do laudo. Prefere redigi-lo por conta própria, inserindo fotografias e esquemas presentes nas normas para um melhor entendimento do documento pelo promotor de justiça. Devido a outras tarefas simultâneas, leva em torno de duas semanas para finalizar o documento.

Dessa maneira observa-se, a partir das informações obtidas, que o modelo de laudo gerado pelo software do Ministério é insuficiente para informar com clareza as melhorias a serem feitas nos ambientes. Além disso, a avaliação deve ser feita manualmente com o instrumento e, logo após, todas as informações e observações devem ser transcritas para o computador, ocasionando um processo lento e com duplicidade de trabalho.

Como ideias para a melhoria da ferramenta foram sugeridos pelos entrevistados: mais espaço no campo de observações para serem elaborados desenhos esquemáticos; a criação de planilhas para novos ambientes (a própria entrevistada mencionou ter criado uma para o caso de postos de saúde); e um sistema que atribuísse valores para os itens a serem atendidos prontamente, tendo em vista que em edificações públicas busca-se atender em curto prazo apenas as prioridades devido à burocracia atribuída aos processo de licitação.

\subsection{Avaliação-Piloto}

A avaliação-piloto teve o intuito de aproximar os pesquisadores da ferramenta estudada e de sua usabilidade, a partir de uma vistoria em edifício educacional. O instrumento é constituído por uma ficha de identificação do edifício avaliado e um total de seis planilhas: Áreas de acesso ao edifício (Planilha 1); Saguões, salas de recepção e espera (Planilha 2); Circulações Horizontais (Planilha 3); Circulações Verticais (Planilha 4); Sanitários (Planilha 5); e Locais para Atividades Coletivas (Planilha 6).

Cada uma consiste em um checklist de perguntas baseadas majoritariamente na legislação vigente, onde o avaliador deve preencher de maneira afirmativa ou negativa, possibilitando ainda a resposta "não se aplica" e um campo para observações relevantes. A Figura 2 ilustra a reprodução da parte inicial da primeira planilha. As perguntas são agrupadas com relação aos elementos que estão sendo avaliados (como pode ser visto na figura, questões relacionadas ao semáforo na via pública). Além disso, também são classificas segundo o componente de acessibilidade ao qual se refere.

Figura 2 - Cabeçalho e início da Planilha 01 - Áreas de Acesso ao Edifício 


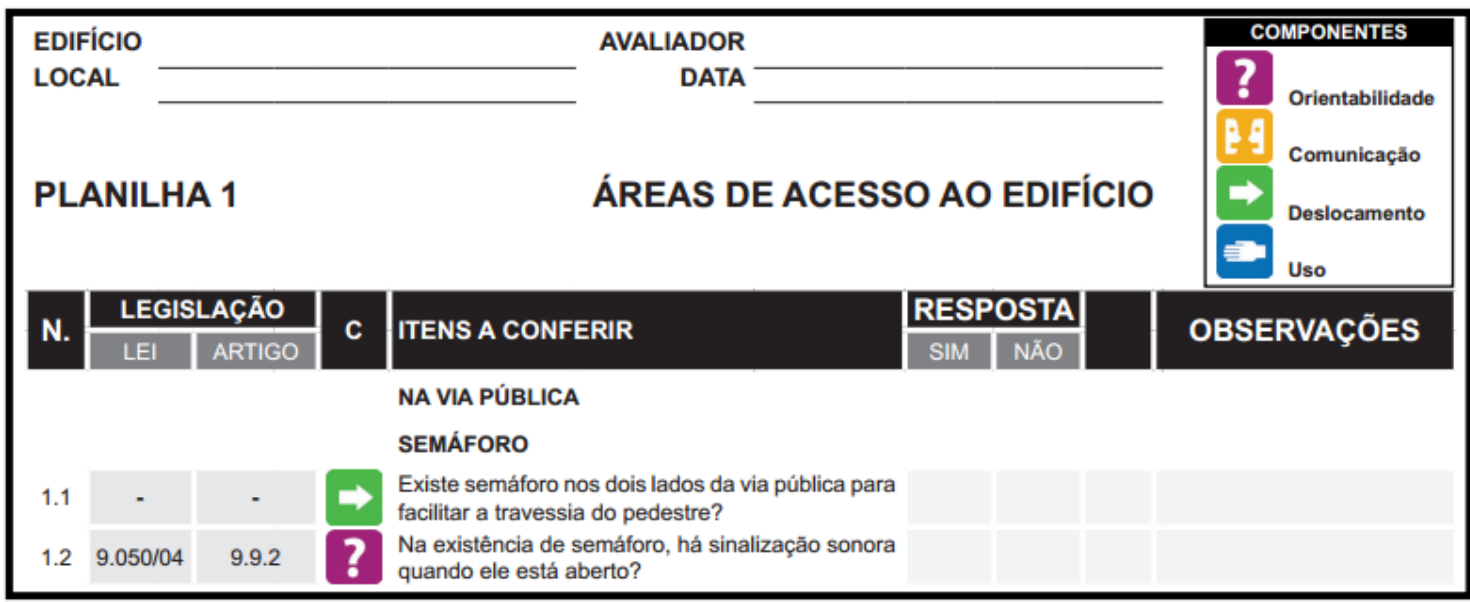

Fonte: Dischinger, Bins Ely e Piardi (2012)

Antes de iniciar a avaliação, ainda na ficha de identificação do edifício, devem ser feitas tanto a planta de situação, ilustrando os acessos ao edifício, quanto uma planta baixa esquemática. Ambas servirão de apoio ao preenchimento das planilhas e realização do laudo técnico, facilitando a localização dos problemas detectados. Para a utilização da ferramenta, também é necessário que o avaliador possua uma planilha para cada ambiente a ser avaliado, necessitando cópias da mesma em número igual à presença do ambiente na edificação. Para que todas as perguntas possam ser respondidas com precisão, tornase necessário o uso de um equipamento de mensuração, como uma trena. Além disso, sugere-se a presença de uma cópia da norma brasileira de acessibilidade, para consulta em caso de dúvidas. Considera-se necessária a presença de no mínimo dois avaliadores para a vistoria, tendo em vista que esta pode-se tornar extensa e de difícil realização para apenas um indivíduo, caso tenha que utilizar todos estes equipamentos.

A avaliação-piloto foi realizada por três avaliadores sem experiência prévia com a ferramenta, porém familiarizados com as normas de acessibilidade. $\mathrm{O}$ primeiro avaliador ficou responsável por preencher as planilhas, o segundo por realizar as medições e o terceiro por registrar aspectos relevantes através de fotografias. Foi avaliado um edifício com área estimada de $3.200 \mathrm{~m}^{2}$ em um período de cerca de duas horas e meia. A plantabaixa esquemática do edifício avaliado pode ser conferida na Figura 3. Destaca-se que a edificação tem três pavimentos, os quais não possuem exatamente a mesma disposição de salas. Considerou-se a duração da avaliação conveniente. $O$ fato ter sido realizada por três pessoas contribuiu para que o tempo fosse melhor aproveitado.

Figura 3 - Planta Baixa esquemática do pavimento térreo do edifício do Departamento de Arquitetura e Urbanismo - UFSC 


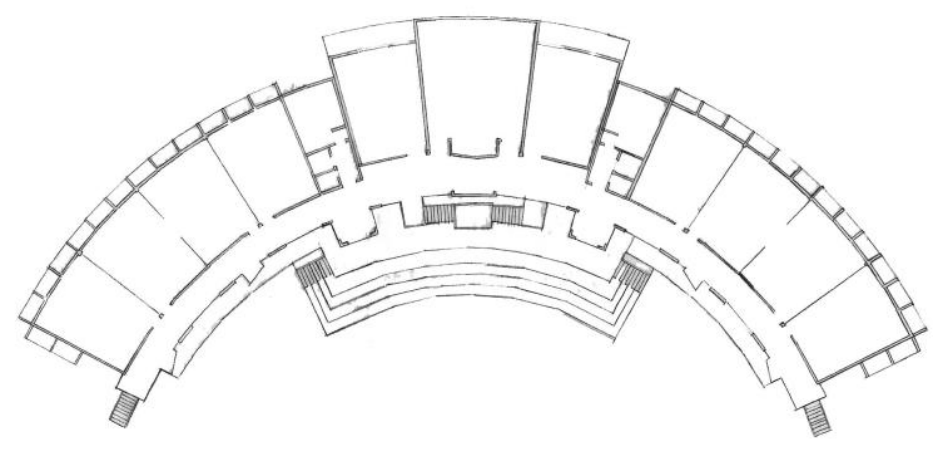

Fonte: Adaptado pelos autores a partir de desenhos do projeto não concluído do edifício.

Para sintetizar as informações da vistoria deve-se realizar o laudo-técnico da avaliação. Como o acesso ao software utilizado para esta tarefa encontra-se restrito aos computadores do Ministério Público, os pesquisadores optaram por realizá-lo manualmente. Dessa maneira, no laudo da avaliação-piloto, seguiu-se o modelo padrão do MP-SC, acrescentando uma coluna extra à direita para a visualização de fotos e croquis representativos. Adicionando o registro de algumas informações visuais, acredita-se facilitar o entendimento do documento. A Figura 4 reproduz parte do laudo realizado.

\section{Figura 4 - Trecho do modelo de laudo realizado para sintetizar as descobertas da}

\section{avaliação-piloto.}

\begin{tabular}{|c|c|c|c|}
\hline \multirow{2}{*}{\multicolumn{4}{|c|}{\begin{tabular}{|l} 
Conclusao \\
Na Via Pública \\
\end{tabular}}} \\
\hline & & & \\
\hline \multicolumn{4}{|l|}{ Passeios } \\
\hline $\begin{array}{l}\text { Ss passeios não têm pisos regulares em qualquer condição } \\
\text { climática. }\end{array}$ & $\begin{array}{l}\text { NBR 9050/04 - Artigo } \\
\text { 6.1.1 }\end{array}$ & - & $\nabla$ \\
\hline $\begin{array}{l}\text { Os passeios não são livres de interferências que impeçam o } \\
\text { deslocamento ou que constituam perigo aos pedestres (postes } \\
\text { de sinalização, vegetaçăo, desniveis, rebaixamentos) }\end{array}$ & $\begin{array}{l}\text { NBR 9050/04 - Artigos } \\
6.10 .7 \text { e } 6.10 .5\end{array}$ & & \\
\hline $\begin{array}{l}\text { Não há sinalização tátil de alerta nos passeios indicando essas } \\
\text { interferências. }\end{array}$ & NBR 9050/04 Artigo 6.1.2 & & \\
\hline
\end{tabular}

Fonte: Desenvolvidos pelos autores.

Como anteriormente citado, para o experimento aqui exposto, as próximas etapas são referentes apenas à primeira planilha - Áreas de Acesso ao Edifício. 


\subsection{Revisão da Planilha}

Após a realização da avaliação-piloto, deu-se continuidade ao procedimento através da revisão da Planilha 01. Foram analisadas todas as perguntas, sendo revistas sua redação, buscando evitar qualquer possibilidade de dupla interpretação. Averiguou-se também a ordem com que cada item era apresentado, visando aprimorar sua continuidade e, finalmente, atualizar as normas e legislações referentes.

Esta etapa resultou em diversas modificações pontuais nos itens das planilhas. Entretanto, ressalta-se que a principal decisão estabelecida neste momento foi a de diminuir a quantidade de informação presente em cada questionamento. Dessa maneira, algumas perguntas que possuíam a presença de mais de um item de avaliação, devido sua disposição no referente artigo normativo, foram desmembradas em mais de uma.

Como exemplo, transcreve-se a pergunta 1.5: "os passeios têm pisos antiderrapantes e regulares em qualquer condição climática?". Tal item está relacionado ao artigo 6.1.1 da NBR 9050/04, que diz "Os pisos devem ter superfície regular, firme, estável e antiderrapante sob qualquer condição [...]". Entretanto, durante a avaliação-piloto os avaliadores se depararam com situações onde apenas um dos aspectos atendia positivamente ao questionamento, e não há como atender de forma parcial um tópico da ferramenta. Dessa maneira, esse item foi desmembrado em dois: o novo item 1.5: "Os passeios têm pisos com superfície antiderrapante em qualquer condição climática?" e o novo item 1.6: "Os passeios têm pisos com superfície regular e estável em qualquer condição climática?". O mesmo procedimento foi realizado para todos os casos semelhantes, aumentando o número final de perguntas, porém sem qualquer interferência na quantidade de aspectos avaliados.

Através da avaliação-piloto foi verificado que alguns questionamentos da planilha eram passíveis de dupla interpretação. Entretanto, isso se dá devido aos próprios artigos referentes à NBR 9050 possuírem ambiguidades. Mesmo estando familiarizados com essa norma, os avaliadores sentiram necessidade de tê-la em mãos para conferir alguns aspectos, tanto no ambiente, quanto nas planilhas. Dessa maneira, acredita-se que a melhor opção para diminuir o risco de se responder inadequadamente uma pergunta é disponibilizando o próprio trecho da legislação referente, sendo interessante a utilização de uma cópia da ABNT 9050/04 durante a vistoria. Esta opção poderia estar disponível facilmente em um instrumento digital, sem a necessidade de aumentar o volume de objetos levados até o local da vistoria.

Além disso, destaca-se a pergunta 1.84, que questiona a respeito da fixação do símbolo internacional de acesso, caso o edifício seja "totalmente acessível de acordo com a NBR 9050/04". Optou-se por retirar essa pergunta da planilha e colocá-la como item a ser respondido após a finalização da vistoria, tendo em vista que só então o avaliador possui capacidade de dizer se a edificação encontra-se realmente totalmente acessível.

Atualmente cada planilha possui categorias de avaliação, as quais contemplam determinados tipos de ambientes e elementos. No caso do edifício vistoriado, alguns deles se repetiam (a categoria "escadas externas", por exemplo, deveria ser completada três vezes). Dessa maneira propõe-se que, antes de responder às perguntas referentes a uma categoria, seja verificado se o ambiente ou elemento está presente no edifício avaliado e, caso esteja, quantos há disponíveis. Assim, em um instrumento digital, essas informações poderiam ser inseridas sem que houvesse a necessidade prévia de possuir cópias das planilhas. 
Tentando solucionar a demanda dos funcionários do Ministério Público levantada durante a entrevista, que dizia respeito à atribuição de valores de prioridade para as perguntas, optou-se por categorizar cada questionamento de duas maneiras diferentes: itens que impedem o acesso e itens que o dificultam. Por exemplo, a não existência de uma rampa em uma rota com desnível configura uma situação de impedimento ao deslocamento para um usuário em cadeira de rodas. Por outro lado, a inclinação excessiva de uma rampa dificulta sua utilização de forma independente, mas não impede o acesso, quando auxiliado. Considera-se que os elementos que impossibilitam a utilização são os que necessitam maior prioridade de adequação.

\subsection{Laudo Técnico}

Assim como no programa do MP-SC em 2005, imagina-se que as avaliações com uma ferramenta digital possam ser executadas por profissionais em formação. Por este motivo, mesmo gerado automaticamente, acredita-se que o laudo só passe a ter validade após revisão e assinatura de um profissional com tal responsabilidade técnica.

O software utilizado pelo MP-SC gerava um laudo-técnico automático, após inseridas as informações em um computador. Um aspecto negativo do laudo realizado pelo MP-SC é sua rigidez, não possibilitando a formatação ou inserção posterior de novas informações. Isso foi verificado tanto pelo relato obtido pela arquiteta entrevistada quanto pela necessidade de serem acrescentadas informações no laudo gerado a partir da avaliaçãopiloto realizada.

O laudo final deve apresentar todas as respostas negativas (itens em desacordo com a norma), sendo classificados entre os que impossibilitam e os que dificultam o acesso. Além disso, deve ser possível categorizá-las por componente de acessibilidade, por elemento avaliado e por planilha, a fim de permitir verificar qual componente e ambiente necessita maior número de adaptações. Acredita-se que possíveis modelos de layout possam ser estudados visando uma disposição melhor das informações, garantindo uma leitura mais simples dos dados.

Acredita-se ainda que possa ser útil para a confecção do laudo a possibilidade de serem anexados, ao seu final, a transcrição dos artigos da legislação em desacordo. A inserção de fotografias e dos textos normativos resulta em um documento final mais extenso. Entretanto, a presença destes elementos torna-se relevante, pois como verificado através da entrevista, o laudo-técnico é encaminhado a um profissional jurídico, que não necessariamente possui conhecimentos acerca de acessibilidade, para a execução do termo de ajuste de conduta. Os registros fotográficos facilitam significativamente a compreensão das características arquitetônicas que estão em desacordo com a norma, possibilitando que até mesmo pessoas não familiarizadas com o assunto identifiquem os problemas.

\section{CONSIDERAÇÕES FINAIS}

A realização deste estudo justifica-se por buscar soluções e diretrizes de forma a agilizar o processo de avaliação da acessibilidade espacial em edificações, tornando-o digitalizado. Através da entrevista realizada, verificou-se a necessidade de pequenas melhorias na ferramenta já existente, porém, a partir das informações obtidas, observouse que o principal agravante na agilidade do processo de avaliação diz respeito ao laudotécnico. O modelo gerado pelo software do MP-SC é insuficiente para informar com 
qualidade as modificações a serem implementadas. Isso faz com que sejam realizados laudos manualmente, demandando mais tempo para sua execução.

Durante a avaliação-piloto efetuada em edifício educacional, a inclusão de plantas baixas esquemáticas, fotografias de aspectos relevantes e descrição dos problemas (observações), no laudo, foi primordial para a definição de estrutura do laudo técnico sugerido, já que no laudo atual há apenas a listagem dos itens da planilha que não estão de acordo com as normas. Dessa maneira, sugere-se atender a esse item para garantir maior compreensão por parte do promotor de justiça encarregado de ler o documento para a realização do termo de ajuste de conduta, possibilitando maior velocidade no processo.

As planilhas utilizadas já são bastante eficazes e práticas para ações de fiscalização quanto ao cumprimento de normas técnicas. Buscou-se manter seu funcionamento, porém tornálo mais simples para o avaliador através do desmembramento de algumas perguntas. Imagina-se como recurso de auxílio na própria ferramenta a presença dos artigos referentes à norma, evitando com que sejam levados diversos objetos para a vistoria. Assim, espera-se que a ferramenta de avaliação seja o mais eficiente possível, minimizando o tempo de trabalho em campo e possíveis erros, e que os laudos gerados por ela sejam mais precisos.

Ainda há muitos edifícios para serem avaliados e adaptados no Brasil. Dessa maneira, as diretrizes aqui estabelecidas podem contribuir para a melhoria de um instrumento capaz de agilizar o processo de garantia ao acesso espacial, proporcionando maior possibilidade de inclusão aos diferentes usuários finais das edificações em um menor período de tempo.

\section{AGRADECIMENTOS}

Às professoras Marta Dischinger e Isabela Fernandes Andrade por colaborarem com a etapa de revisão das planilhas e aos bolsistas do PET Computação da IES pelo auxílio prestado no decorrer da pesquisa.

\section{REFERÊNCIAS}

ASSOCIAÇÃO BRASILEIRA DE NORMAS TÉCNICAS (ABNT). NBR-9050: Acessibilidade a edificações, mobiliário, espaços e equipamentos urbanos. Rio de Janeiro, 2004.

BRASIL. Decreto $\mathbf{N}^{\mathbf{0}} \mathbf{5 . 2 9 6}$ de $\mathbf{2}$ de dezembro de 2004. Disponível em: < http://www.planalto.gov.br/ccivil_03/_ato2004-2006/2004/decreto/d5296.htm>. Acesso em: 29 abr. 2014.

COHEN, R; DUARTE, C. R. S. D; BRAsileiro, A. B. H. Acessibilidade a Museus. Ministério da Cultra. Instituto Brasileiro de Museus - Brasília, DF. Ibram, 2012. 190p.

DISCHINGER, M; BINS ELY, V.H.M.; PIARDI, S.M.D.G. Promovendo acessibilidade espacial nos edifícios públicos. Programa de Acessibilidade às Pessoas com Deficiência ou Mobilidade Reduzida nas Edificações de Uso Público, 2012. Florianópolis, Ministério Público de Santa Catarina.

ELALI, Gleice Azambuja; ARAÚJO, Rosineide Gomes de; PINHEIRO, José de Queiroz. Acessibilidade Psicológica: Eliminar barreiras "físicas" não é suficiente. In: Desenho Universal: caminhos da acessibilidade no Brasil. ORSNTEIN, Sheila Walbe et al. São Paulo: Annablume, 2010. P117 - 127.

FAVERO, Eugenia Augusta Gonzaga. Direitos das Pessoas com Deficiência: Garantia de Igualdade na Diversidade. Rio de Janeiro: WVA Ed., 2004.

MARCONI, M. A.; LAKATOS, E. M. Fundamentos de Metodologia Científica. 7. ed. São Paulo: Atlas, 2010. 297 p. 